\title{
Effects of Inspiratory Exercise With Linear and Nonlinear Load on Respiratory Variables Post-Bariatric Surgery
}

\author{
Eli Maria Pazzianotto-Forti, Carolina Moraes da Costa Munno, Daniela Faleiros Bertelli Merino, \\ Maura Rigoldi Simões da Rocha, Tamires Alessa de Mori, and Irineu Rasera Júnior
}

\begin{abstract}
BACKGROUND: Obesity leads to changes in respiratory function, causing reduced lung volumes and mechanical disadvantage of the respiratory muscles. We sought to evaluate the effect of breathing exercises using devices that impose linear and nonlinear load on reversing diaphragm dysfunction and the prevalence of atelectasis after bariatric surgery. METHODS: This was a blind randomized clinical trial. Preoperatively, we assessed the subjects' maximum inspiratory pressure by measuring nasal inspiratory pressure and respiratory muscle endurance with an incremental test based on sustained maximum inspiratory pressure (sustained $\mathbf{P}_{\mathbf{I m a x}}$ ) and the prevalence of atelectasis by chest radiograph. Subjects were then randomized into 2 groups: a linear load pressure group and nonlinear load pressure group; both groups received conventional respiratory physiotherapy. Subjects were reassessed on the second day after bariatric surgery. RESULTS: We included 40 morbidly obese women (body mass index $>40 \mathrm{~kg} / \mathrm{m}^{2}$ ), age $25-55$ years, who underwent bariatric surgery by laparotomy. The groups were homogeneous with respect to age $(P=.11)$, body mass $(P=.12)$, height $(P=.75)$, body mass index $(P=.75)$, nasal inspiratory pressure $(P=.48)$, sustained $P_{I \max }(P=.89)$, and absence of atelectasis at baseline. In the reassessment, both groups showed significant reduction in nasal inspiratory pressure $(P<.001)$ and maintenance of sustained $P_{\text {Imax }}$ (linear load pressure $P=.51$; nonlinear load pressure $P=.055$ ). The prevalence of atelectasis was $15 \%$ for linear load pressure and $25 \%$ for nonlinear load pressure, with no significant difference between groups $(P=.69)$. CONCLUSION: Both groups were able to maintain respiratory muscle endurance after bariatric surgery. In addition, the treatment contributed to controlling atelectasis so that it did not cause clinical repercussions to the subjects. (ClinicalTrials.gov registration NCT02298517). Key words: postoperative period; physical therapy specialty; breathing exercises; respiratory muscle; obesity; gastroplasty. [Respir Care 2019;64(12):1516-1522. (C) 2019 Daedalus Enterprises]
\end{abstract}

\section{Introduction}

Obesity is a metabolic disease characterized by the accumulation of fat deposited mainly in the subcutaneous adipose tissue. Excess weight has significant consequences

\footnotetext{
Drs Pazzianotto-Forti and Merino, Ms Moraes da Costa Munno, Ms Simões da Rocha, and Ms de Mori are affiliated with the Graduate Program in Physical Therapy and Human Movement Sciences, School of Health Sciences, Universidade Metodista de Piracicaba, Piracicaba, São Paulo, Brazil. Dr Rasera is affiliated with the Center of Gastroenterology and Obesity Surgery of Piracicaba, Piracicaba, São Paulo, Brazil.
}

The authors have disclosed relationships with Coordenação de Aperfeiçoamento de Pessoal de Nível Superior (CAPES) and Conselho Nacional de Desenvolvimento Científico e Tecnológico (CNPQ). for the lives of obese individuals, leading to various problems from discrete physiological symptoms to serious morbidities that may affect quality of life and life expectancy. ${ }^{1}$

Regarding respiratory function, obesity can compromise lung function as a result of the excess fat deposited on the chest and abdomen, which reduces lung volume and capacity. ${ }^{2}$ These changes are even more evident after surgical procedures, particularly upper abdominal surgeries that

\footnotetext{
Correspondence: Eli Maria Pazzianotto-Forti PhD, Rodovia do Açúcar, km 156 (SP-308), 13.423-170, Piracicaba, São Paulo, Brazil. E-mail: eli.forti@unimep.br.
}

DOI: $10.4187 /$ respcare. 05841 
involve the manipulation of abdominal viscera, use of subdiaphragmatic retractors, and incisions. ${ }^{3}$

Due to the unsatisfactory results of other methods of weight reduction, bariatric surgery is considered the standard procedure for the treatment of severe obesity. ${ }^{4,5}$ In an attempt to minimize complications in the bariatric surgery postoperative period, Casali et $\mathrm{al}^{6}$ studied the effects of breathing exercises using devices with load in obese subjects after gastroplasty and concluded that respiratory muscle training improves inspiratory muscle strength and endurance and contributes to the early recovery of lung flow, volume, and capacity.

Despite the importance of pre- and postoperative physiotherapy in patients undergoing abdominal surgery, Lawrence et $\mathrm{al}^{7}$ concluded that there is a lack of evidence regarding the best methods of respiratory physiotherapy to treat these patients. In addition to this gap in the literature, there is a lack of standardization with regard to the number of sessions and the interval between them, given that the effects of certain methods seem to be dose- and timedependent. ${ }^{8-10}$

The aim of this study was to evaluate the effect of breathing exercises using devices that impose linear and nonlinear load on reversing diaphragm dysfunction on the prevalence of atelectasis after bariatric surgery.

\section{Methods}

\section{Study Design}

This was a blind randomized clinical trial conducted in accordance with the standards of conduct of experimental research with human subjects, after being approved by the Ethics Committee of the Methodist University of Piracicaba (UNIMEP) under Approval No. 54/13.

\section{Sample Calculation}

The calculation of sample size was performed using BioEstat version 5.3 (Instituto Mamirauá, Tefé, Amazonas, Brazil) along with descriptive statistics, based on a pilot study, considering the variable nasal inspiratory pressure. The minimum difference between the means of the treatments and the standard deviation of the error was used for the calculation. Based on the analysis of variance test and assuming an alpha of 0.05 and a statistical power of 0.80 , the sample size required was 20 subjects in each group, for a total of 40 subjects.

\section{Inclusion and Exclusion Criteria}

We evaluated morbidly obese patients admitted to a hospital in the city of Piracicaba, São Paulo, Brazil, from February 2014 to February 2015, who met the following

\section{QUICK LOOK}

\section{Current knowledge}

Despite the importance of pre- and postoperative physiotherapy in patients undergoing abdominal surgery, there is a lack of evidence regarding methods of respiratory physiotherapy to treat and monitor respiratory muscle behavior in the postoperative period. However, this is important because respiratory muscle dysfunction is the main cause of pulmonary complications and may delay or affect the postoperative outcome of morbidly obese patients after abdominal surgery.

\section{What this paper contributes to our knowledge}

All treatments proposed with both linear and nonlinear inspiratory loads were effective in maintaining the inspiratory muscle endurance. This is relevant because muscle endurance reflects the respiratory muscles' ability to support loads. Increased demand can occur with respiratory complications (eg, infections, wheezing and accumulation of mucus) with a subsequent increase in airway resistance, and in situations that require greater energy expenditure.

inclusion criteria: body mass index $40-55 \mathrm{~kg} / \mathrm{m}^{2}$, age $25-$ 55 years, eligibility for Roux-en-Y gastric bypass surgery by laparotomy (open surgery), and preoperative spirometric and radiological tests within normal parameters. The exclusion criteria were as follows, according to the history reported by the patients and described in the medical records: smoking habit, asthma, COPD, obstructive sleep apnea, and presence of atelectasis, hemodynamic instability in the postoperative period, presence of surgical complications (eg, fistula in the clipping line, gastrointestinal bleeding, intestinal obstruction), and patients who refused to participate in the study until its completion or were unable to comprehend the performance of the evaluations or the proposed treatment (Figure 1).

\section{Randomization}

The randomization process was performed using Microsoft Excel 2007 (random table) in blocks of 10 subjects, allocating them into either the linear load pressure group or the nonlinear load pressure group.

\section{Blinding}

The therapist who conducted the pre- and postoperative assessments was blind to the treatment received; the researcher who performed the randomization was blind to 


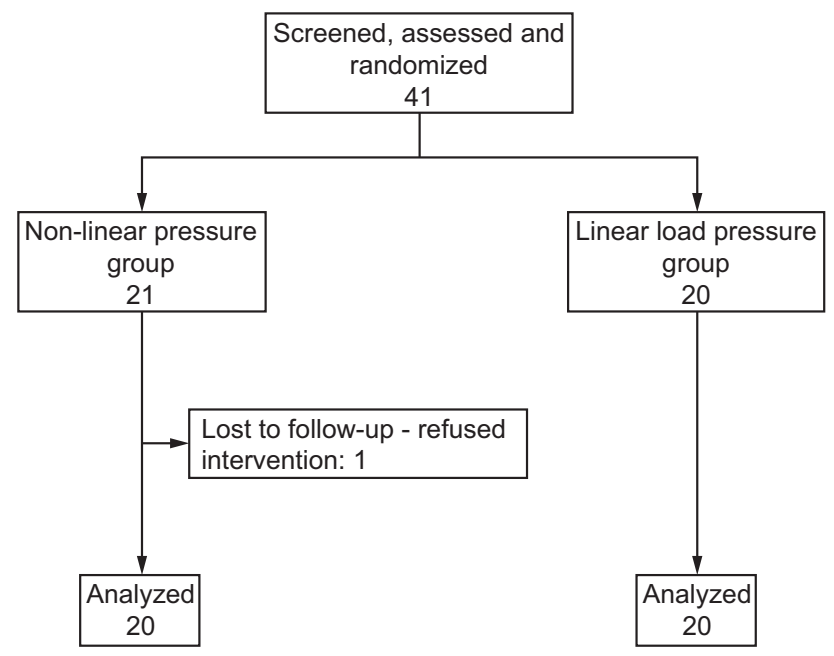

Fig. 1. Flow chart.

the clinical data and the assessments of the subjects; and the therapist who performed the treatments was blind to the assessments and data analysis. Subjects were blinded to treatments received.

\section{Assessments}

Following hospital admission, the subjects were assessed preoperatively for inspiratory muscle strength and endurance. The same measures were reassessed on the second day after bariatric surgery (ie, postoperative).

Assessment of Respiratory Muscle Strength. Inspiratory muscle strength was assessed by measuring nasal inspiratory pressure and maximal inspiratory pressure $\left(\mathrm{P}_{\text {Imax }}\right)$ with a digital manometer (MVD 300, GlobalMed, Porto Alegre, RS, Brazil). Nasal inspiratory pressure was measured during the sniff technique, ${ }^{11}$ in which the subject is sitting and performs a "maximum sniff" with a closed mouth from functional residual capacity. ${ }^{11}$ Subjects performed 10 maneuvers, ${ }^{12,13}$ with a 30 -s rest interval between each one. $\mathrm{P}_{\text {Imax }}$ was assessed to establish the initial loading of the respiratory muscle endurance test and the loading of the device with linear load. The $\mathrm{P}_{\text {Imax }}$ was measured during exertion starting from residual volume, and each subject performed 3-5 acceptable and reproducible maneuvers. The time interval between consecutive measurements was $1 \mathrm{~min}$. For the study, we considered the highest value for both variables. ${ }^{14}$

Assessment of Respiratory Muscle Endurance. Respiratory muscle endurance was assessed using the K3 Powerbreathe device (Gaiam, Southam, United Kingdom). The subjects remained seated and received standardized instructions and encouragement to achieve the best perfor- mance during the test. The subjects were asked to take long, deep breaths followed by slow and maximum expirations in each breathing cycle. Each stage of the test consisted of 30 cycles, which were determined by a beep emitted by the device after cessation of the expiratory flow. The initial test load was $30 \%$ of the previously evaluated $\mathrm{P}_{\text {Imax }} \cdot{ }^{15}$ After completion of each stage, the subject rested for $1 \mathrm{~min}$. At each new stage, an increment of $10 \mathrm{~cm} \mathrm{H}_{2} \mathrm{O}$ was applied until the predetermined pressure could not be reached after 3 consecutive breaths or until dyspnea occurred. The highest load sustained for at least 15 breaths was considered the sustained $\mathrm{P}_{\operatorname{Imax}}$ value.

Power is defined as the amount of work performed per unit of time. It is calculated by the interaction of flow and load every $2 \mathrm{~ms}$ and integrates this for the entire session. Power combines the force exerted by inspiratory muscles and the volume of air inhaled. The training index is the amount of mechanical energy (or work) achieved during a session expressed as a percentage of the maximum potentially achievable work (ie, the amount of work possible to achieve training at absolutely $100 \%$ effort). The training index gives an indication of how much effort was achieved into training in the section.

Chest Radiograph. The assessment of the prevalence of atelectasis pre and postoperatively was based on the reports of posterior-anterior chest radiograph, requested as part of hospital routine and issued by the hospital's radiologist, who was blinded to the group to which any subject belonged. In the preoperative period, the presence of atelectasis was considered to be an exclusion criterion. Therefore, none of the subjects included in the study presented preoperative atelectasis. The reports that showed presence of atelectasis, hypoinflation of the lungs or of lung fields, regardless of size and location, were computed.

\section{Interventions}

Conventional respiratory physiotherapy was performed once in the immediate postoperative and twice sessions in the first postoperative day and was composed of diaphragmatic breathing exercises, deep breathing exercises, fractional breathing in 2 and 3 times, and breathing exercises combined with upper limb movements. For every exercise, a series of 10 repetitions was performed. Exercises for the prevention of deep vein thrombosis and ambulation were also performed. ${ }^{16}$

The proposed treatments with inspiratory loads were performed twice in the immediate postoperative period shortly after the subject woke up from sedation, and five times on postoperative day 1 , with intervals of $3 \mathrm{~h}$ between them.

For both treatments, subjects were instructed to remain seated with their feet supported. The linear load pressure 
used a PowerBreathe device (Powerbreathe K3, Gaiam), which has a fast response valve controlled electronically to create resistance to inspiration. To start the exercise, subjects held the device by the lower posterior end, leaving the exhalation valve free. The exercises were performed with inspiratory resistance of $40 \%$ of the $\mathrm{P}_{\text {Imax }}{ }^{6,17}$ Subjects were instructed to inhale with sufficient force to overcome the resistance of the device, and then to exhale normally. This group performed 6 sets of 15 repetitions, with a rest interval of 30-60 s between sets.

The nonlinear load pressure used an inspiratory muscle training device (DHD 22-7500, Diemolding Healthcare Division, Canastota, New York) with nonlinear load. This device has flow-resistive inspiratory loading that requires inspirations through holes of different diameters. ${ }^{18}$ Each device includes 6 color-coded resistors for setting the resistance level. In this study, resistance was standardized and all subjects used the red hole ( $2 \mathrm{~mm}$ in diameter). This resistor was sufficient to impose respiratory load for all subjects treated. The subjects were asked to perform explosive, quick, and intense inspirations and normal expirations in 6 sets of 15 breaths with intervals of 30-60 s between sets.

Before starting the treatment or postoperative assessment, pain was evaluated using the visual analog scale (VAS) with scores ranging from 0 to 10 . When pain was classified as $\leq 4$, the treatment or evaluation was conducted normally; when pain was classified as $>4$, an analgesic was given and pain was classified again after $30 \mathrm{~min}$. All subjects received analgesics as needed, and all had pain ${ }^{19}$ classified as $\leq 4$ on VAS after $30 \mathrm{~min}$. All subjects received the same number of therapies per day.

\section{Statistical Analysis}

Statistical analysis was performed using BioEstat version 5.3. The Shapiro-Wilk test was used to verify the normality of the data. For intragroup comparison (pre- and postoperative), we used the paired $t$ test or the Wilcoxon test. For comparison between groups preoperatively and for the analysis of the values of the difference between the pre- and postoperative periods between the groups, Student $t$ or Mann-Whitney tests were used. The Fisher exact test was used to compare the prevalence of atelectasis between groups. The level of statistical significance was $P<.05$.

\section{Results}

Of the 41 randomized and evaluated subjects, one was excluded for refusing to complete the proposed treatment. Thus, 40 subjects were assessed and randomly allocated into one of the 2 groups: the linear load pressure group, or the nonlinear load pressure group. Both groups also re-
Table 1. Subject Characteristics

\begin{tabular}{lccc}
\hline \hline & LLP Group & NLP Group & $P$ \\
\hline Age, y & $39.35 \pm 6.33$ & $37.4 \pm 8.48$ & .11 \\
Body mass, kg & $116.47 \pm 14.37$ & $113.87 \pm 28.11$ & .12 \\
Height, cm & $159.55 \pm 5.20$ & $162 \pm 4.63$ & .75 \\
Body mass index, kg/m ${ }^{2}$ & $45.64 \pm 3.94$ & $45.16 \pm 3.9$ & .75 \\
Systolic blood pressure, & $142.3 \pm 18.3$ & $144.9 \pm 16.2$ & .15 \\
$\quad$ mm Hg & & & \\
Diastolic blood pressure, & $88.1 \pm 12.4$ & $88.9 \pm 13.1$ & .17 \\
$\quad$ mm Hg & $10(50)$ & $12(60)$ & .60 \\
Diabetes type 2 & $8(40)$ & $10(50)$ & .60 \\
Hypertension & $10(50)$ & $11(550)$ & .52 \\
Dyslipidemia & $127 \pm 11.12$ & .64 \\
Duration of mechanical & $128.14 \pm 10.75$ & & \\
$\quad$ ventilation, min & & 3 & \\
Length of stay, d & 3 & & \\
$\quad$ & & & \\
Each group has $n=20$ subjects. Values are expressed as mean \pm SD or $n(\%)$. & \\
LLP = linear load pressure & & & \\
NLP = nonlinear load pressure & & & \\
\hline
\end{tabular}

Table 2. Comparison Between Groups

\begin{tabular}{lccc}
\hline \hline & LLP Group & NLP Group & $P$ \\
\hline Nasal inspiratory pressure, & $86 \pm 22.24$ & $90.95 \pm 21.75$ & .48 \\
$\quad$ cm $\mathrm{H}_{2} \mathrm{O}$ & & & \\
Sustained $\mathrm{P}_{\text {Imax }}, \mathrm{cm} \mathrm{H}_{2} \mathrm{O}$ & $43 \pm 11.29$ & $44.5 \pm 13.95$ & .89 \\
Power, W & $3.4 \pm 1.55$ & $3.54 \pm 1.67$ & .63 \\
Volume, L & $1.78 \pm 0.34$ & $1.9 \pm 0.39$ & .30 \\
Training index, $\%$ & $88.4 \pm 12.07$ & $85.75 \pm 11.11$ & .41 \\
& & & \\
Each group has $n=20$ subjects. Values are expressed as mean $\pm \mathrm{SD}$. & \\
LLP = linear load pressure & & & \\
NLP = nonlinear load pressure & & & \\
\hline
\end{tabular}

ceived also conventional respiratory physiotherapy, with 20 subjects in each group.

Table 1 shows the age, anthropometric, clinical, and surgical characteristics of the subjects in both groups. There was no difference between the groups for these variables, in preoperative (baseline) $(P>.05)$. Table 2 shows a comparison between groups, preoperative, for the nasal inspiratory pressure measurements and the variables for the respiratory muscle endurance test (sustained $\mathrm{P}_{\text {Imax }}$, power, volume, and training index) in the linear load pressure and nonlinear load pressure (baseline) groups. There were no between-group differences in nasal inspiratory pressure, but there were significant reductions in the nasal inspiratory pressure, power and volume variables in the postoperative for the two groups. Table 3 shows the variables obtained in the strength test (nasal inspiratory pressure) and the respiratory muscle endurance test for each group in the pre- and postoperative assessments, as well as a comparison of the differences between the pre- and post- 
Table 3. Comparisons Between Pre- and Postoperative Values and Between Results of the Strength Test and the Respiratory Muscle Endurance Test

\begin{tabular}{|c|c|c|c|c|c|c|c|}
\hline & \multicolumn{3}{|c|}{ LLP Group } & \multicolumn{3}{|c|}{ NLP Group } & \multirow{2}{*}{$P$ (Difference) } \\
\hline & Pre & Post & Difference & Pre & Post & Difference & \\
\hline \multicolumn{8}{|c|}{ Nasal inspiratory pressure, $\mathrm{cm} \mathrm{H}_{2} \mathrm{O}$} \\
\hline Media & 86 & 68 & -18 & 90.95 & 65.7 & -25.25 & .15 \\
\hline $\mathrm{SD}$ & 22.24 & 25.19 & 18.04 & 21.75 & 20.51 & 23.03 & \\
\hline$P$ value (before and after) & \multicolumn{3}{|c|}{$<.001$} & \multicolumn{2}{|c|}{$<.001$} & & \\
\hline \multicolumn{8}{|l|}{ Sustained $\mathrm{P}_{\operatorname{Imax}}, \mathrm{cm} \mathrm{H}_{2} \mathrm{O}$} \\
\hline Media & 43 & 41.5 & -1.05 & 44.5 & 39.5 & -5 & .20 \\
\hline $\mathrm{SD}$ & 11.29 & 13.48 & 9.88 & 13.95 & 13.56 & 10.51 & \\
\hline$P$ value (before and after) & \multicolumn{2}{|c|}{.51} & & \multicolumn{2}{|c|}{.055} & & \\
\hline \multicolumn{8}{|l|}{ Power, W } \\
\hline Media & 3.4 & 2.27 & -1.14 & 3.54 & 2.52 & -1.02 & .83 \\
\hline $\mathrm{SD}$ & 1.55 & 0.95 & 1.52 & 1.67 & 1.83 & 1.46 & \\
\hline$P$ value (before and after) & \multicolumn{2}{|c|}{$<.001$} & & \multicolumn{2}{|c|}{$<.001$} & & \\
\hline \multicolumn{8}{|l|}{ Volume, L } \\
\hline Media & 1.78 & 1.37 & -0.42 & 1.9 & 1.39 & -0.51 & .35 \\
\hline $\mathrm{SD}$ & 0.34 & 0.36 & 0.31 & 0.39 & 0.30 & 0.49 & \\
\hline$P$ value (before and after) & \multicolumn{2}{|c|}{$<.001$} & & \multicolumn{2}{|c|}{$<.001$} & & \\
\hline \multicolumn{8}{|l|}{ Training index, $\%$} \\
\hline Media & 88.4 & 90.65 & 2.25 & 85.75 & 82.2 & -3.55 & .76 \\
\hline SD & 12.07 & 12.06 & 15.01 & 11.11 & 22.6 & 23.48 & \\
\hline$P$ value (before and after) & \multicolumn{3}{|c|}{.45} & \multicolumn{2}{|c|}{.68} & & \\
\hline \multicolumn{8}{|l|}{$\begin{array}{l}N=40 \text { subjects. Values are express } \\
\text { LLP }=\text { linear load pressure } \\
\text { NLP }=\text { nonlinear load pressure } \\
\text { Pre }=\text { preoperative } \\
\text { Post = postoperative }\end{array}$} \\
\hline
\end{tabular}

operative assessments. There were no between-group differences in nasal inspiratory pressure, but there were significant reductions in the nasal inspiratory pressure,power and volume variables in the postoperative for the two groups. However, the sustained $\mathrm{P}_{\mathrm{Imax}}$ and training index values were maintained postoperatively compared to the preoperative period. In the comparison of the values of the differences, there was no significant difference between groups.

The prevalence of atelectasis was evaluated with chest radiograph performed on postoperative day 2 (ie, the day of discharge). Atelectasis was found in $15 \%$ of subjects in the linear load pressure group and $25 \%$ of the subjects in the nonlinear load pressure group, with no significant difference between the proportions $(P=.69)$.

\section{Discussion}

In this study, inspiratory muscle strength, as assessed with nasal inspiratory pressure, was lower in the postoperative phase regardless of the treatment, and when comparing the difference between the pre- and postoperative outcomes, there was no significant difference between the treatments. The significant reduction in inspiratory muscle strength can be understood in this study as characteristic of the diaphragm dysfunction that occurs in the postoperative phase of abdominal surgery and not necessarily as muscle weakness.

Such reduction in nasal inspiratory pressure identifies the muscle inefficiency triggered by factors inherent in the surgery such as anesthesia, incisions, and pain. ${ }^{6}$ According to Fagevik Olsen et al, ${ }^{20}$ this reduction could also be found at the time of reassessment, which occurred approximately $48 \mathrm{~h}$ after surgery. This finding demonstrates that this time may not be sufficient for the recovery of respiratory muscle strength, given that the diaphragmatic function takes approximately $7-10 \mathrm{~d}$ to return to preoperative values. ${ }^{20}$

Inspiratory muscle endurance (ie, the ability to maintain contractile strength against resistive inspiratory loading) is also significantly affected in individuals undergoing upper abdominal surgeries. In this study, the methodology aimed to maintain the inspiratory muscle endurance with low loads and a high number of repetitions.

All treatments proposed with both linear and nonlinear inspiratory loads were effective in maintaining the inspiratory muscle endurance assessed by sustained $\mathrm{P}_{\text {Imax }}$. This is 
relevant because, in this study specifically, muscle endurance reflects the ability of the respiratory muscle to support loads. ${ }^{21}$ This increased demand can occur during respiratory complications (eg, infections, wheezing, and accumulation of mucus) with subsequent increase in airway resistance, ${ }^{22}$ and in situations that require greater energy expenditure such as hiking, climbing up and going down stairs, or simply daily activities that such patients are likely to perform after hospital discharge. Thus, the reduction in respiratory muscle endurance may delay or affect the postoperative outcomes of morbidly obese patients who have undergone bariatric surgery. ${ }^{23}$ In Casali et al, ${ }^{6}$ the subjects performed inspiratory exercises with loading for $30 \mathrm{~d}$ after bariatric surgery and showed improved respiratory muscle endurance over the course of the study. The findings of those authors corroborate the results of the present study.

Regarding the variable respiratory muscle endurance, both groups showed the same results, that is, significant reduction in postoperative values in the variables power and volume and maintenance of training index. No significant difference was found between treatments in the analysis of the difference value. Power is a measure of muscle performance that combines strength and speed of movement. This value refers to the mean of all inspirations performed during the test. Volume indicates the average amount of air inhaled with each inhalation during the test. Thus, the results of this study led to the conclusion that post-surgical inspiratory volumes and muscle performance were lower in both groups.

The variable training index refers to the recruitment capacity of the muscles and indicates the effectiveness of the test, combining contractile strength and test time. In our study, the training index remained the same in both groups, (ie, the breathing exercise programs with linear or nonlinear inspiratory loading elicited stronger inspiratory muscle contractions during the test). This finding demonstrates that the methodology of intervention as described here can promote the maintenance of respiratory muscle endurance even after a short time of treatment. Thus, these techniques may be useful to reverse diaphragmatic dysfunction earlier.

Our methodology of the incremental endurance test was performed in an innovative way. The device we used has the advantage of digital load adjustments and provides data for power, volume, and training index, which were useful for understanding the behavior of respiratory muscles after bariatric surgery.

The study by Villiot-Danger et $\mathrm{al}^{24}$ emphasizes the importance of respiratory muscle training in these patients. It evaluated the effect of respiratory muscle endurance training on the respiratory muscles, dyspnea symptoms, and exercise capacity in hospitalized obese subjects. The results showed that respiratory muscle endurance exercise is feasible in obese patients and may help improve dyspnea and exercise capacity.

Regarding atelectasis, there was a prevalence of $25 \%$ for the nonlinear load pressure group and $15 \%$ for the linear load pressure group, but there were no significant between-group differences. It is worth nothing that all cases of atelectasis were subclinical.

General anesthesia is known to increase the incidence of atelectasis more frequently in obese patients. This is considered a common problem during surgery and in anesthetic recovery rooms. ${ }^{25}$ In morbidly obese patients, anesthesia accentuates the reduction in functional residual capacity, promoting early narrowing of the small airways and leading to a greater degree of hypoxemia and increased incidence of atelectasis. ${ }^{26,23}$

In addition, the incidence of atelectasis is $45 \%$ higher in obese patients who underwent upper abdominal surgery than in the general population. ${ }^{27}$ As observed in the present study, Ferreira et $\mathrm{al}^{9}$ reported that atelectasis is considered the most common postoperative complication in obese subjects submitted to gastroplasty, with incidence varying according to the type of surgery and the treatment provided. However, it usually resolves spontaneously and does not have significant clinical importance.

The treatment program using exercises with load starting in the early postoperative period is considered critical to the resolution of atelectasis, given that pulmonary complications typically develop within the first $6 \mathrm{~h}$ after surgery. ${ }^{28}$

\section{Limitations}

The non-inclusion of men in this study makes it difficult to generalize our results for both genders. However, women constitute the majority of patients who use bariatric surgery as a method to achieve weight reduction as well as reduction of comorbidities. Chest radiograph to measure atelectasis is considered an insensitive exam for this measurement, although this exam is part of the hospital postoperative routine.

\section{Conclusion}

Both groups were able to maintain respiratory muscle endurance after bariatric surgery. This finding is extremely important because the postoperative period can further increase respiratory demand in these individuals. In addition, the cases of atelectasis noted in this study were too mild to have clinical effects on the subjects. Thus, the results suggest that the maintenance of respiratory muscle endurance can help prevent respiratory failure in obese patients and thus contribute to the success of the surgery. 


\section{INSPIRATORY EXERCISES POST-BARIATRIC SURGERY}

\section{REFERENCES}

1. Horvath TL. The hardship of obesity: a soft-wired hypothalamus. Nature Neurosci 2005;8(5):561-565.

2. Rasslan Z, Saad Junior R, Stirbulov R, Fabbri RMA, Lima CAC. Evaluation of pulmonary function in class I and II obesity. J bras pneumol 2004;30(6):508-514.

3. Melero A, Vallés J, Vila P, Canet J, Vidal F. Recuperación anestésica, intercambio gaseoso y función hepática y renal postoperatorios en pacientes con obesidad mórbida sometidos a cirugía bariátrica: comparación de los efectos del halotano, isoflurano y fentanil. Rev Esp Anestesiol Reanim 1993;40(5):268-272.

4. Santos JED. Obesity surgery and satiety control. Sao Paulo Med J 2006;124(4):179-180

5. Geloneze S, Geloneze B, Morari J, Matos-Souza J, Lima M, Chaim E, et al. PGC1 $\alpha$ gene Gly482Ser polymorphism predicts improved metabolic, inflammatory and vascular outcomes following bariatric surgery. Int J Obes 2012;36(3):363-368

6. Casali CCC, Pereira APM, Martinez JAB, de Souza HCD, Gastaldi AC. Effects of inspiratory muscle training on muscular and pulmonary function after bariatric surgery in obese patients. Obes surg 2011;21(9):1389-1394.

7. Lawrence VA, Cornell JE, Smetana GW. Strategies to reduce postoperative pulmonary complications after noncardiothoracic surgery: systematic review for the American College of Physicians. Ann Intern Med 2006;144(8):596-608.

8. Pessoa KC, Araújo GF, Pinheiro AN, Ramos MR, Maia SC. Noninvasive ventilation in the immediate postoperative of gastrojejunal derivation with Roux-en-Y gastric bypass. Braz J Phys Ther 2010; 14(4):290-296.

9. Ferreira F, Moreira F, Parreira VF, Franco V. Ventilação não invasiva no pós-operatório de cirurgias abdominais e cardíacas-revisão da literatura. Rev Bras Fisioter 2002;6(2):47-54.

10. Joris JL, Sottiaux TM, Chiche JD, Desaive CJ, Lamy ML. Effect of bi-level positive airway pressure (BiPAP) nasal ventilation on the postoperative pulmonary restrictive syndrome in obese patients undergoing gastroplasty. Chest 1997;111(3):665-670.

11. Heritier F, Rahm F, Pasche P, Fitting JW. Sniff nasal inspiratory pressure: a noninvasive assessment of inspiratory muscle strength. Am J Respir Crit Care Med 1994;150(6):1678-1683.

12. Lofaso F, Nicot F, Lejaille M, Falaize L, Louis A, Clement A, et al. Sniff nasal inspiratory pressure: what is the optimal number of sniffs? Eur Respir J 2006;27(5):980-982.

13. Uldry C, Fitting JW. Maximal values of sniff nasal inspiratory pressure in healthy subjects. Thorax 1995;50(4):371-375
14. Neder JA, Andreoni S, Lerario MC, Nery LE. Reference values for lung function tests: II. Maximal respiratory pressures and voluntary ventilation. Braz J Med Biol Res 1999;32(6):719-727.

15. American Thoracic Society, European Respiratory Society. ATS/ERS statement on respiratory muscle testing. Am J Respir Crit Care Med 2002;166(4):518-624.

16. Forti E, Ike D, Barbalho-Moulim M, Rasera Jr I, Costa D. Effects of chest physiotherapy on the respiratory function of postoperative gastroplasty patients. Clinics 2009;64(7):683-689.

17. Barros GF, Santos CS, Granado FB, Costa PT, Límaco RP, Gardenghi G. Respiratory muscle training in patients submitted to coronary arterial bypass graft. Braz J Cardiovasc Surg 2010;25(4):483490

18. McConnell A, Romer L. Respiratory muscle training in healthy humans: resolving the controversy. Int J Sports Med 2004;25(4):284293.

19. Downie WW, Leatham PA, Rhind VM, Wright V, Branco JA, Anderson JA. Studies with pain rating scales. Anna Rheum Dis 1978; 37(4):378-381.

20. Fagevik Olsen M, Hahn I, Nordgren S, Lönroth H, Lundholm K. Randomized controlled trial of prophylactic chest physiotherapy in major abdominal surgery. Br J Surg 1997;84(11):1535-1538.

21. Pereira ÉF, Teixeira CS. Proposta de valores normativos para avaliação da aptidão física em militares da Aeronáutica. Rev Bras Educ Fís Esporte 2006;20(4):249-256.

22. Junior A, Costa JO, Giannini CG, Saragiotto DF. Desafios no manuseio peri-operatório de pacientes obesos mórbidos: como prevenir complicações. Rev Bras Anestesiol 2003;53(2):227-236.

23. Eichenberger A-S, Proietti S, Wicky S, Frascarolo P, Suter M, Spahn D, et al. Morbid obesity and postoperative pulmonary atelectasis: an underestimated problem. Anesth Analg 2002;95(6): 1788-1792.

24. Villiot-Danger J, Villiot-Danger E, Borel J, Pépin J, Wuyam B, Verges S. Respiratory muscle endurance training in obese patients. Int J Obes 2011;35(5):692-699.

25. Blouw EL, Rudolph AD, Narr BJ, Sarr MG. The frequency of respiratory failure in patients with morbid obesity undergoing gastric bypass. AANA J 2003;71(1):45-50.

26. Ogunnaike BO, Jones SB, Jones DB, Provost D, Whitten CW. Anesthetic considerations for bariatric surgery. Anesth Analg 2002; 95(6): 1793-1805

27. Øberg B, Poulsen T. Obesity: an anaesthetic challenge. Acta Anaesthesiol Scand 1996;40(2):191-200.

28. Helling TS, Willoughby TL, Maxfield DM, Ryan P. Determinants of the need for intensive care and prolonged mechanical ventilation in patients undergoing bariatric surgery. Obes Surg 2004;14(8):10361041 . 